\title{
Thromboembolism in COVID-19 Patient with Unilateral Congenital Absent ICA with Intracranial Aneurysm: First Case Report
}

Diwakar Shankar ( $\sim$ dev123diwakar@gmail.com )

Dr Ram Manohar Lohia Institute of Medical Sciences https://orcid.org/0000-0003-4752-6168

Deepak Kumar Singh

Dr Ram Manohar Lohia Institute of Medical Sciences

Vipin Chand

Dr Ram Manohar Lohia Institute of Medical Sciences

Kuldeep Yadav

Dr Ram Manohar Lohia Institute of Medical Sciences

\section{Research Article}

Keywords: COVID-19, Intracranial aneurysm, Thromboembolism in COVID-19, Absent ICA, Giant aneurysm, Vascular anomaly

Posted Date: August 13th, 2021

DOI: https://doi.org/10.21203/rs.3.rs-741390/v1

License: (9) This work is licensed under a Creative Commons Attribution 4.0 International License. Read Full License 


\section{Abstract}

We here discuss an interesting case of COVID-19 patient suffering from ruptured right supra-clinoid intracranial aneurysm with congenital absence of right ICA. COVID-19 has been responsible for over 175 million reported cases and over 3.8 million deaths world-wide. Severe cases of COVID-19 is characterized with cytokine outburst and hyperinflammation, platelet activation, endothelial dysfunction and sepsis related coagulopathy. This predisposes for thromboembolic events and aneurysm formation and rupture. Agenesis, aplasia and hypoplasia of internal carotid artery (ICA) is a rare congenital anomaly. ICA agenesis is associated with increased incidence of intracranial aneurysm as compared with general population.

\section{Introduction}

According to World Health Organization (WHO), as of now COVID-19 has been responsible for over 191 million reported cases and over 4.1 million deaths world-wide. Severe cases of COVID-19 are characterized with cytokine outburst and hyperinflammation, platelet activation, endothelial dysfunction and sepsis related coagulopathy. This predisposes for thromboembolic events and aneurysm formation and rupture. Though venous thromboembolism (VTE) is more common than arterial, there had been case series suggesting increased incidence of arterial thromboembolic events (ATE) in COVID-19 patients. Also, agenesis, aplasia and hypoplasia of internal carotid artery (ICA) is a rare congenital anomaly with incidence of $<0.01 \%$ in general population[11]. ICA agenesis has been associated with increased incidence of intracranial aneurysm (25-43\%) as compared with general population (2-4\%). We here discuss one interesting case of COVID-19 patient suffering from ruptured right supra-clinoid intracranial aneurysm with congenital absence of right ICA. A rare case that has never been reported before.

\section{Case Report}

A 47-years-old male patient complained of sudden onset severe headache associated with loss of consciousness eight days prior to presentation. At the time of presentation he was COVID-19 RT-PCR positive. On admission GCS was E4V5M6, Hunt and Hess grade 2 with no sensory / motor / autonomic neurological deficit. High resolution CT thorax and chest skiagram was done which showed post-covid changes in lungs (Figure 1). NCCT Brain suggestive of minimal SAH in basal cistern (Figure 2). CT Angiography Brain vessels showed right supra-clinoid aneurysm (Figure 3). Patient was taken for digital subtraction angiography (DSA) to better delineate anatomy following all necessary COVID-19 guideline for operation theatre. A 6-French $11 \mathrm{~cm}$ femoral access sheath (Medtronic Inc, Minneapolis, USA) was used for groin access on the right side. A 6-French $100 \mathrm{~cm}$ Envoy guide catheter (Codman, Wokingham, UK) was used to access bilateral common carotid artery (CCA) and vertebral arteries (VA). A Terumo $150 \mathrm{~cm}$ guide wire (Terumo Europe, Leuven, Belgium) was used to guide the catheter. Selective angiogram of the right common carotid artery (CCA) showed hypoplastic stump of the right ICA (Figure 4). Selective angiogram of the left vertebral artery showed an aneurysm measuring $5.6 \mathrm{~mm} \times 6.5 \mathrm{~mm} \times 9.8 \mathrm{~mm}$ filling from right posterior communicating artery (P.com.) (Figure 5). Aneurysm also filled from the left anterior 
cerebral artery (ACA) through anterior communicating artery (A.com) (Figure 6). Also the right ACA and middle cerebral artery (MCA) was supplies by left ACA via A.com (Figure 7). Post-procedure DSA showed absent flow in the bilateral ACA and right MCA (Figure 8). Immediately intra-arterial administration of rtPA (alteplase $(0.9 \mathrm{mg} / \mathrm{kg})$ along with Abciximab $(4 \mathrm{mg})$ was given but with no success. Post-procedure CT Head showed right MCA and bilateral ACA territory infarct (Figure 9). Patient was taken emergency decompressive craniectomy but he sustained cardiac arrest couple of minutes thereafter and didn't survive.

\section{Discussion}

Agenesis, aplasia and hypoplasia of internal carotid artery (ICA) is a rare congenital anomaly with incidence of $<0.01 \%$ in general population. Tode, in 1787 , was first to report ICA agenesis on post-mortem exam[7]. Verbiest was first to report the same on angiography in 1954[14].

Some more than 100 cases have been reported in the past. Padget described that ICA arises from the dorsal aorta and the third aortic arch at 4-5 mm embryonic stage and entirely develops by 6 weeks[8]. This developmental anomaly occurs due to mechanical stress resulting from pressure effects and excessive folding of cephalic portion of embryo and amniotic bands[5]. Also the carotid canal develops in association with the ICA. The skull-base begin to form during the 5th-6th weeks of fetal life. Thus, if ICA does not develop or fails to develop before the 5th embryonic week, the ICA and the carotid canal remains undeveloped $[5,6]$. The external carotid artery (ECA) and common carotid artery (CCA) arise from the aortic sac independently and can present normally in a case of ICA agenesis as was seen in our case[15].

Diagnosis of an absent ICA is made on CT/CT angiography and digital subtraction angiography (DSA). Non-visualization of an ICA on angiography and absent bony carotid canal in the base of the skull on CT is helps in the diagnosis of congenital absence of an ICA.

Most of the patients are asymptomatic because of the collateral circulation. Tsuruta and Myazaki proposed three types of collateral channels through the circle of Willis[12]. In Type I, the ipsilateral ACA is supplied by the contralateral ICA, opposite to the ICA agenesis, through the anterior communicating artery (A.Com.). The MCA is supplied by the basilar artery through the posterior communicating artery. In Type II, the ipsilateral ACA and MCA are supplied by the contralateral ICA through patent A.Com. In Type III, the ipsilateral ACA and MCA are supplied by the transcranial anastomoses that develop from ECA or contralateral ICA or primitive vessels. Our case had Type II anomaly.

Sometimes patients with congenital absent ICA develops subarachnoid hemorrhage (SAH) due to ruptured aneurysm or transient ischemic attack (TIA) due to vascular insufficiency. ICA agenesis has been associated with increased incidence of intracranial aneurysm (25-43\%) as compared with general population $(2-4 \%)[12,4]$. Lee et.al. found that aneurysm develops ipsilateral to absent ICA as was in our case, supporting a congenital origin of aneurysm as opposed to hemodynamic factors. 
COVID-19 infection occurs through the severe acute respiratory syndrome coronavirus 2 (SARS-CoV-2) virion binding to Angiotensin Converting Enzyme 2 (ACE-2), an enzyme responsible for regulation of blood pressure and has anti-atherosclerotic effects. SARS-CoV-2 binds to Angiotensin Converting Enzyme-2 (ACE-2) and inactivates it. Also, SARS-CoV-2- ACE-2 binding is responsible for direct damage to the BBB $[9,10]$.

COVID-19 is characterized by cytokine outburst and hyperinflammation, platelet activation, endothelial dysfunction and sepsis related coagulopathy leading to increased risk of aneurysm formation or rupture. Pro-inflammatory cytokines in COVID-19 such as interleukin (IL)-1, IL-6, and TNF are found to be responsible for the loss of vascular integrity. Kandula et al. in his study found that the hypercytokinemia of sHLH (Secondary Hemophagocytic Lymph Histiocytosis) may result in endothelial injury through increased vascular permeability, resultant ischemia of the vascular endothelium, and cell damage. Severe COVID-19 infections have a similar cytokine profile as SHLH[3]. Moriguchi et al. found that cytokine cascade has been directly demonstrated to be responsible for neurological disorders and acute cerebrovascular disease[1]. Brian et. al. in his study suggested that the state of hyperinflammation is responsible for increased chance of aneurysm formation and rupture in patients with COVID-19 infection[2].

COVID-19 is also responsible for thromboembolic event which was seen in our patient. COVID-19 has an increased incidence of thromboembolic events (TE), Venous TE (VTE) more common than arterial TE (ATE)[15]. Some report incidence of (TE) to be $20-30 \%$ in COVID-19 patients and some reported up to $40-70 \%$ of their cases. This was associated with higher rate of mortality patients with COVID-19 as was in our case[13].

\section{Conclusion}

Congenital absence of internal carotid artery is an extremely rare disorder which is associated with intracranial aneurysm formation, more commonly on the ipsilateral side. This when combined with the inflammatory response of hypercytokinemia in COVID-19 leads to degradation of cerebral vasculature and aneurysm formation or rupture. It was also seen that COVID-19 has increased incidence of thromboembolic events which is associated with increased mortality. Though this case was first of its kind where COVID-19 was associated with intracranial aneurysm rupture with congenital absent ICA and thromboembolism. Further, long-term retrospective studies will be needed to determine the effects of COVID-19 on intracranial aneurysm and thromboembolism and postulate guidelines to prevent and treat the same.

\section{Declarations}

\section{i. Funding:}

Not Applicable 


\section{ii. Conflicts of interest/Competing interests:}

Author, Diwakar Shankar declares that he has no conflict of interest. Author, Deepak Kumar Singh declares that he has no conflict of interest. Author, Vipin Chand declares that he has no conflict of interest. Author, Kuldeep Yadav declares that he has no conflict of interest.

\section{iii. Ethics approval:}

All procedures performed in studies involving human participants were in accordance with the ethical standards of the institutional and/or national research committee and with the 1964 Helsinki declaration and its later amendments or comparable ethical standards.

\section{iv. Consent to participate:}

Informed consent was obtained from all individual participants included in the study.

\section{v. Consent for publication:}

Yes

\section{vi. Availability of data and material:}

Yes

\section{vii. Code availability:}

Not Applicable

\section{viii. Authors' contributions:}

All authors were involved in the planning and writing of this paper.

\section{References}

1. de Melo Espíndola O, Siqueira M, Soares CN, de Lima MA, Leite AC, Araujo AQ, et al. Patients with COVID-19 and neurological manifestations show undetectable SARS-CoV-2 RNA levels in the cerebrospinal fluid. Int J Infect Dis. 2020;96:567-9. 
2. Fiani B, Fowler JB, Figueras RA, Hessamian K, Mercado N, Vukcevich O, et al. Ruptured cerebral aneurysms in COVID-19 patients: A review of literature with case examples. Surg Neurol Int. 2021;12:187.

3. Kandula M, Eichenauer S, Ahmed U, Fischer J. Secondary hemophagocytic lymphohistiocytosis presenting as acalculous cholecystitis. Am J Gastroenterol. 2017;112:690.

4. Kunishio K, Yamamoto Y, Sunami N, Asari S. Agenesis of the left internal carotid artery, common carotid artery, and main trunk of the external carotid artery associated with multiple cerebral aneurysms. Surg Neurol. 1987;27:177-81.

5. Lee JH, Oh CW, Lee SH, Han DH. Aplasia of the internal carotid artery. Acta Neurochir (Wien). 2003;145:117-25.

6. Morris P. Practical Neuroangiography. Philadelphia: Lippincott Williams and Wilkins; 1997. p. 148.

7. Orakd gen M, Berkman Z, Ersahin M, Biber N, Somay H. Agenesis of the left internal carotid artery associated with anterior communicating artery aneurysm: Case report. Turk Neurosurg. 2007;17:273-6.

8. Padget $\mathrm{DH}$. The development of the cranial arteries in the human embryo. Contrib Embryol. 1948.;32:207-62.

9. Pavlov V, Beylerli O, Gareev I, Solis LF, Herrera AS, Aliev G. COVID-19-related intracerebral hemorrhage. Front Aging Neurosci. 2020;12:600172.

10. Poyiadji N, Shahin G, Noujaim D, Stone M, Patel S, Griffith B. COVID-19-associated acute hemorrhagic necrotizing encephalopathy: Imaging features. Radiology. 2020;296:E119-20.

11. Smith KR Jr, Nelson JS, Dooley JM Jr. Bilateral "hypoplasia”of the internal carotid arteries. Neurology. 1968;18:1149-56.

12. Tsuruta J, Myazaki Y. A case of complete absence of the internal carotid artery associated with an aneurysm of anterior communicating artery. No To Shinkei. 1977;5:895-900.

13. Tang N, Li D, Wang X, Sun Z. Abnormal coagulation parameters are associated with poor prognosis in patients with novel coronavirus pneumonia. J Thromb Haemost. 2020;18(4):844-7. doi:10.1111/jth. 14768 .

14. Verbiest $H$. Radiological findings in a case with absence of the left internal carotid artery and compression of several cranial nerve roots in the posterior fossa by the basilar artery. Med Contemp. 1954;72:601-9.

15. Yokochi K, Iwase K. Bilateral internal carotid artery agenesis in a child with psychomotor developmental delay. Pediatr Neurol. 1996;15:76-8.

\section{Figures}



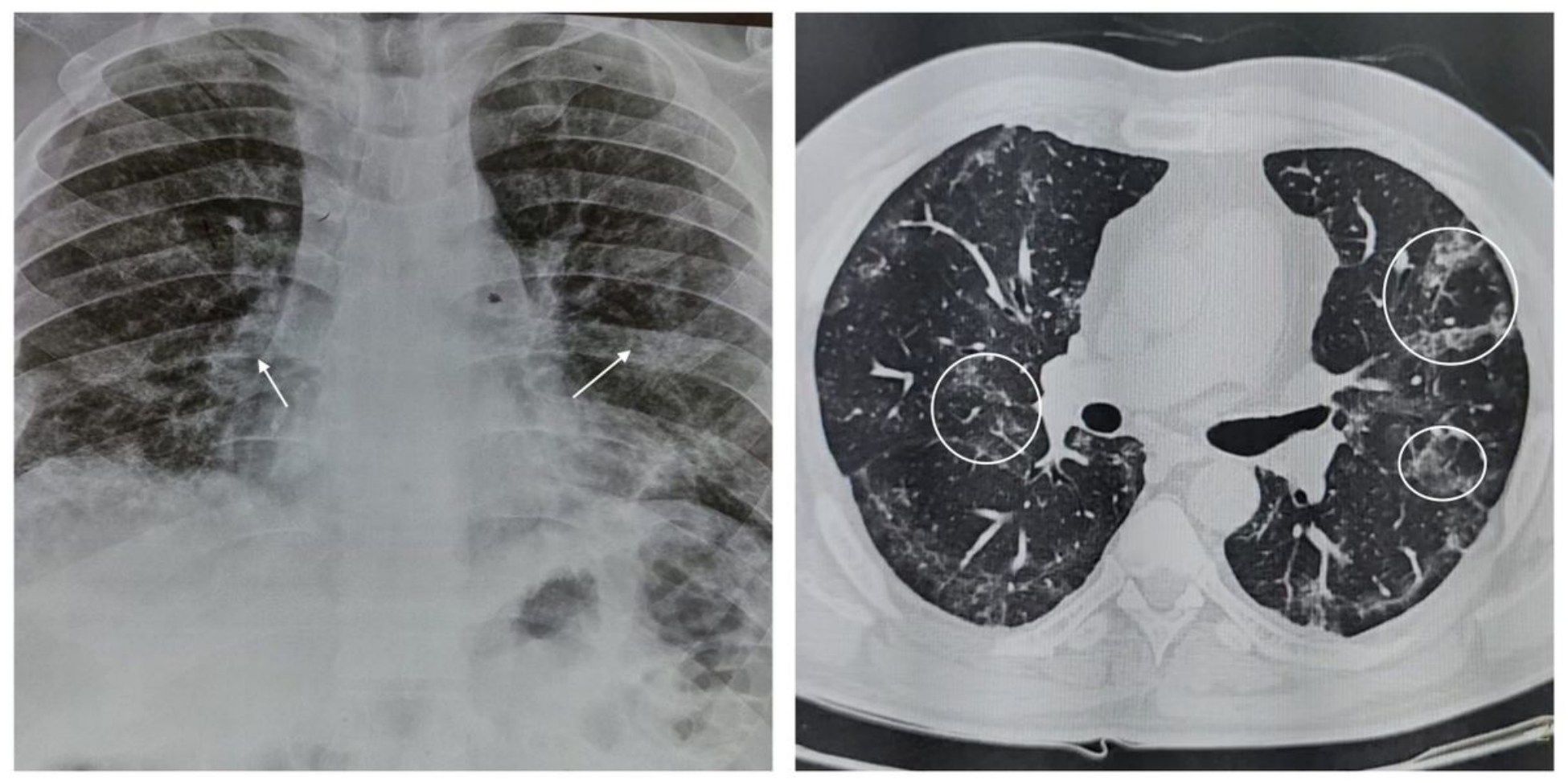

Figure 1

Chest Skiagram and High Resolution Computer Tomography (HRCT) Thorax showing post COVID-19 changes. 


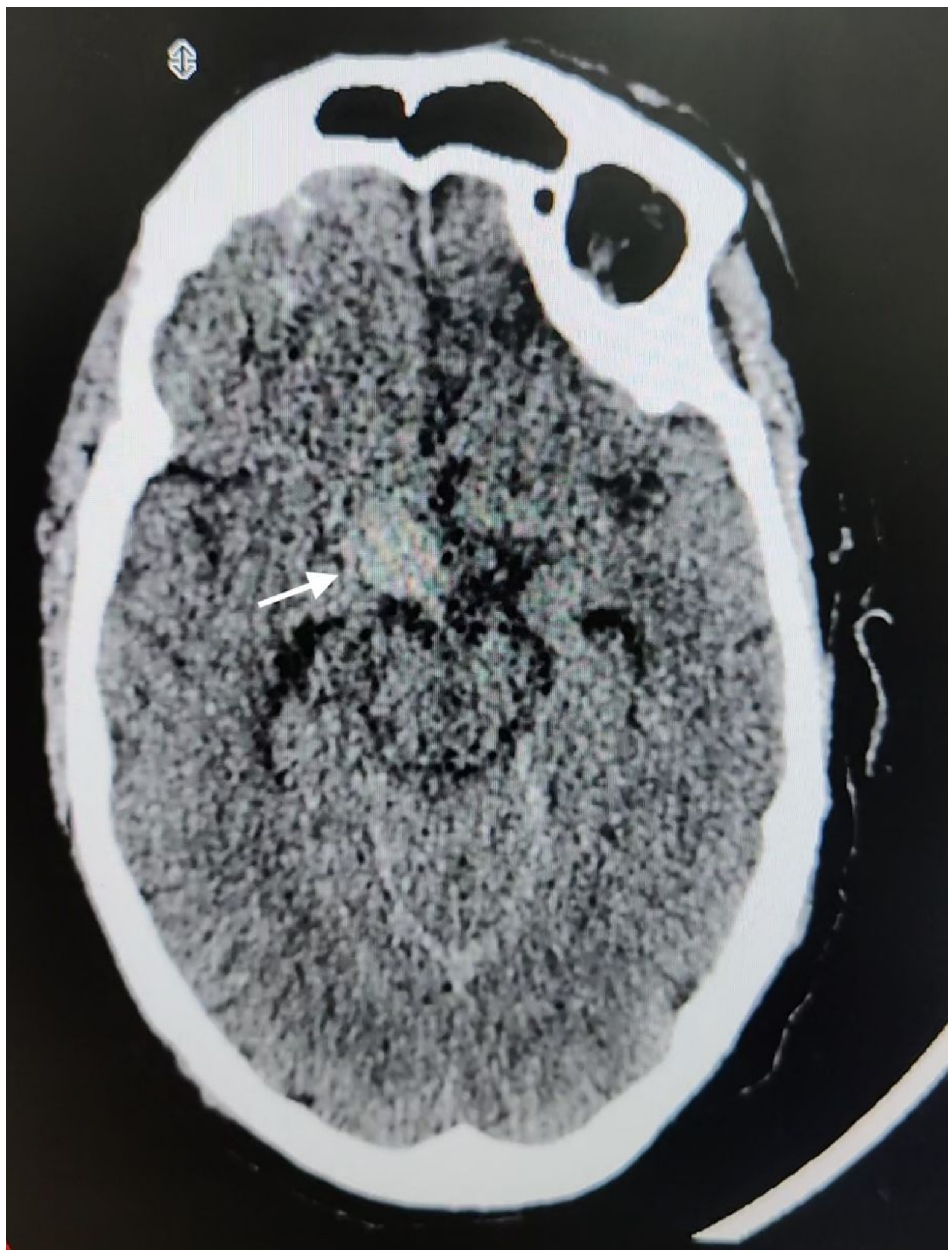

Figure 2

Pre-op Computer Tomography Head with sub-arachnoid haemorrhage (SAH). 

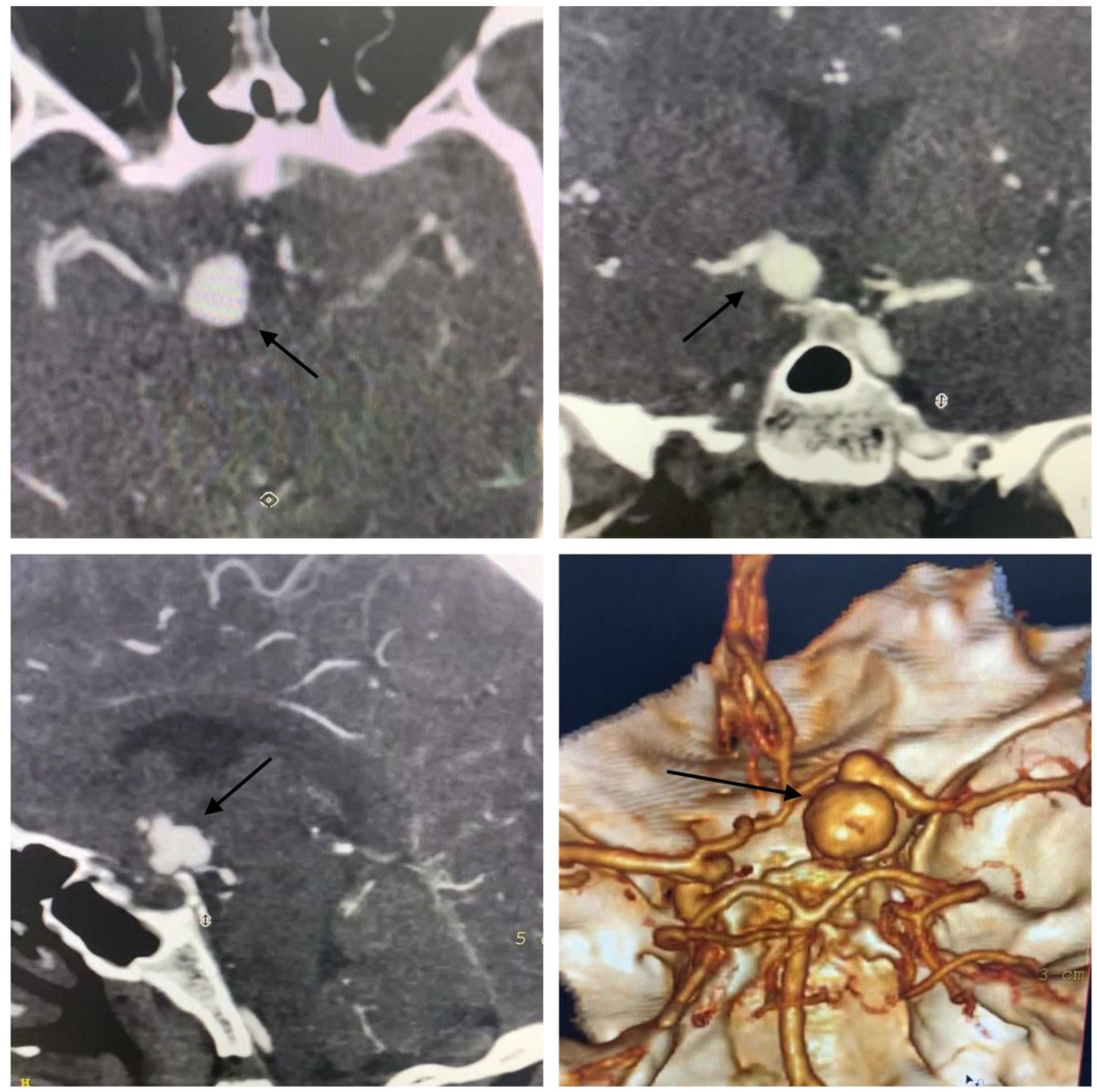

\section{Figure 3}

Pre-op Computer Tomography Angiography showing right supra-clinoid aneurysm. 

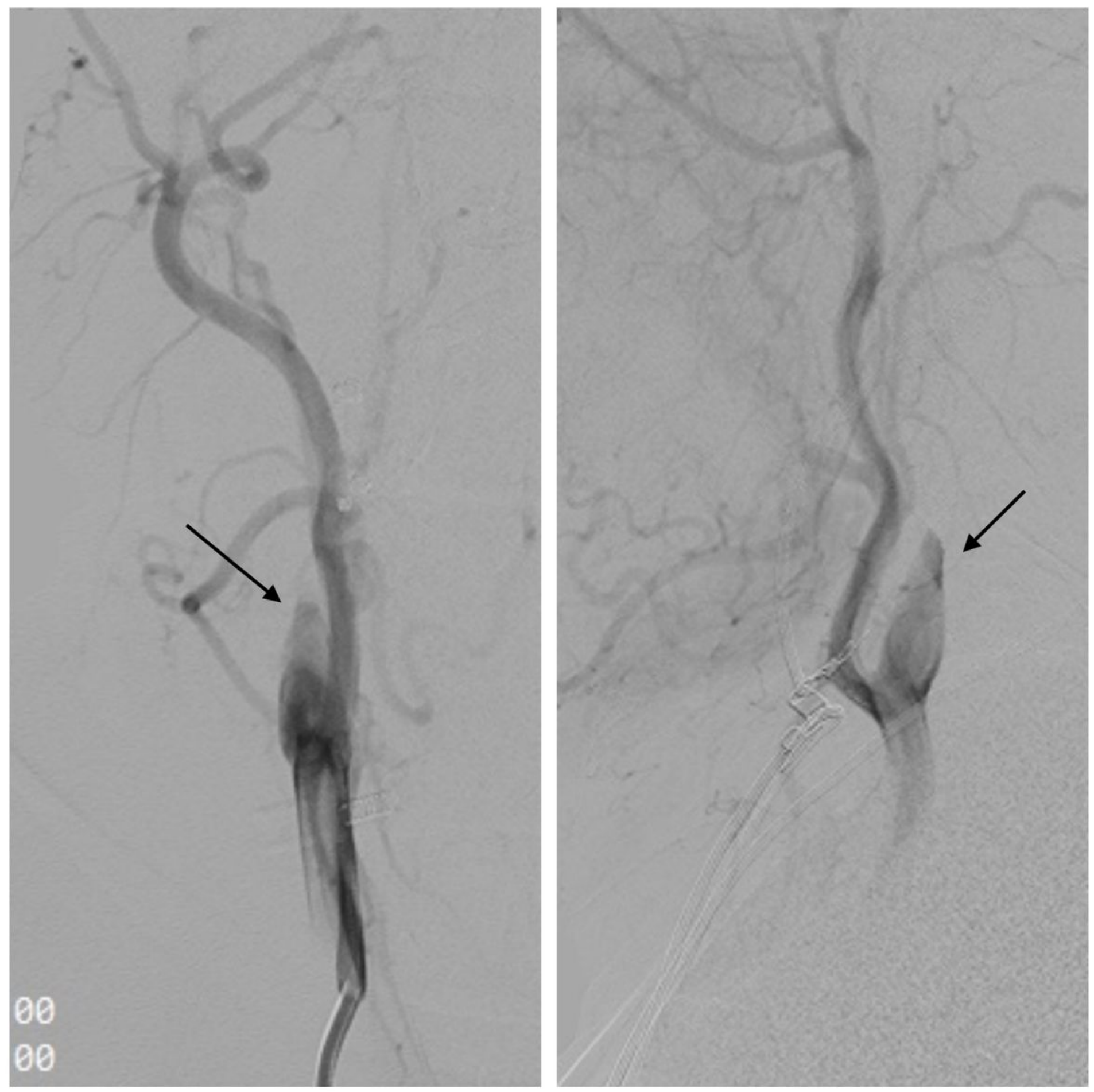

\section{Figure 4}

DSA right common carotid artery (CCA) showing hypoplastic right internal carotid artery (ICA). 

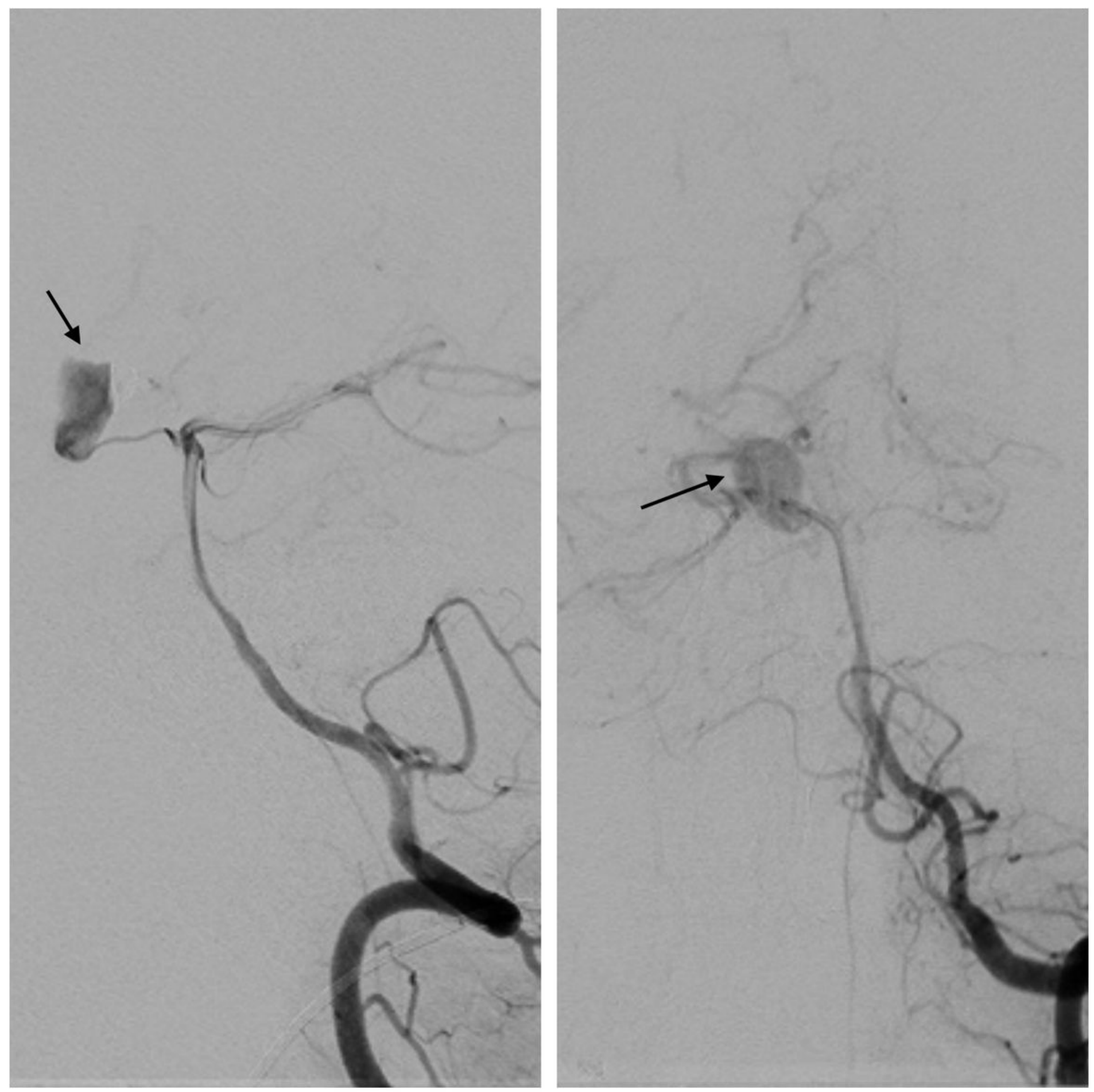

Figure 5

Digital Subtraction Angiography (DSA) of left vertebral artery showing aneurysm filled from right posterior communicating artery (P.com.A). 

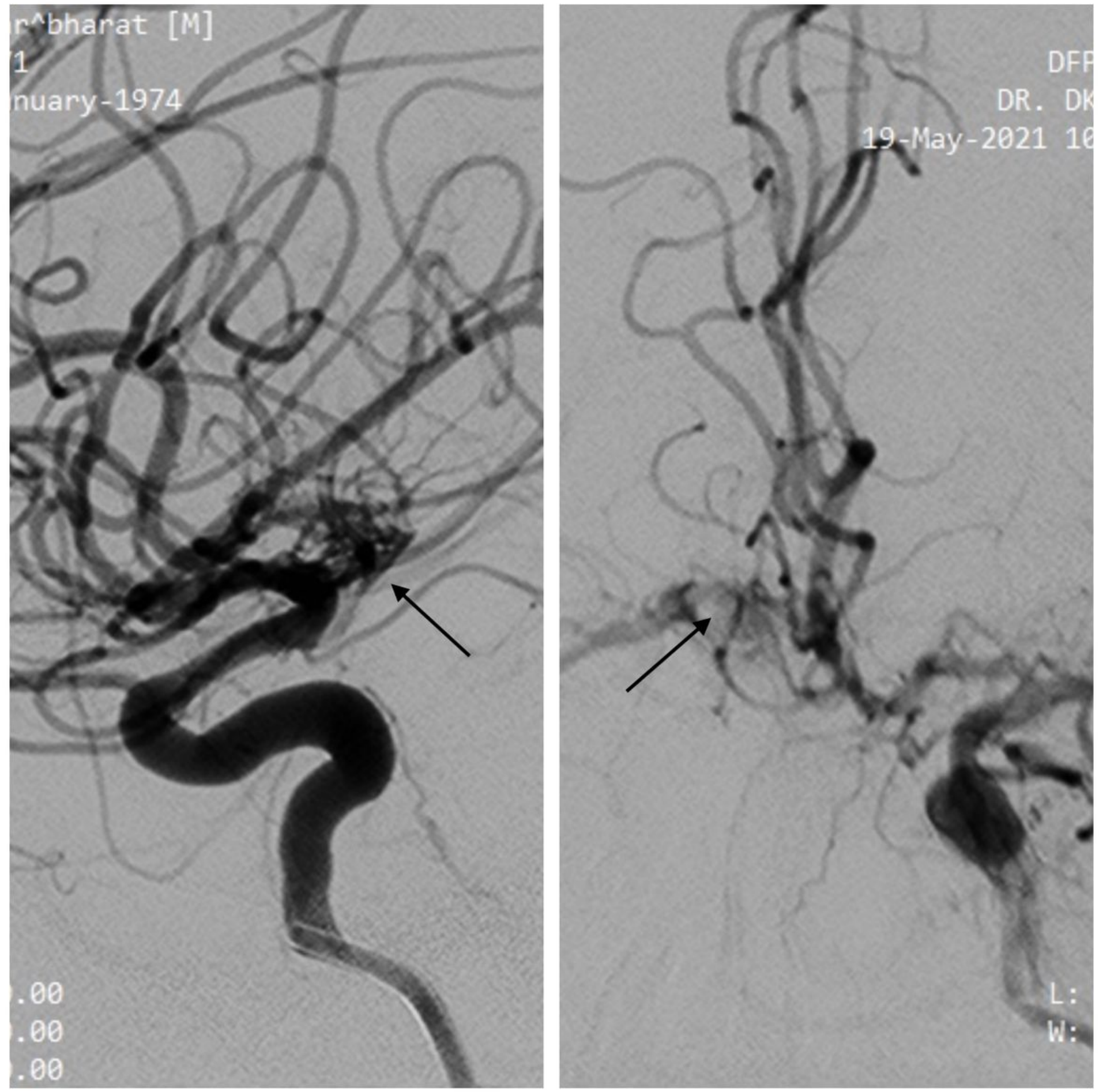

\section{Figure 6}

Digital Subtraction Angiography (DSA) left internal carotid artery (ICA) showing aneurysm filled from left Anterior Cerebral Artery (ACA) via anterior communicating artery (A.com.A). 

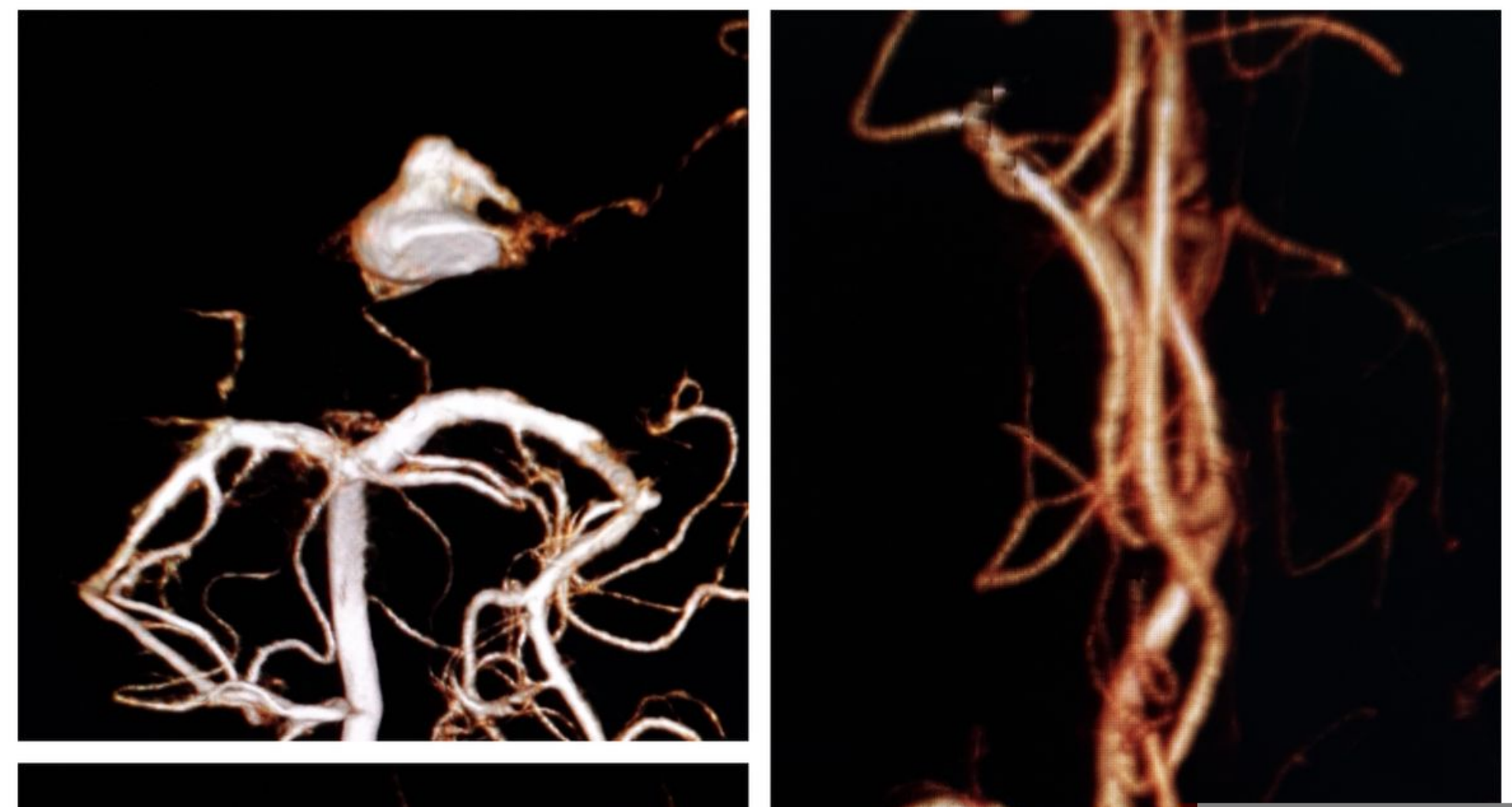

Figure 7

3D reconstruction of Digital Subtraction Angiography (DSA) images showing aneurysm with its communications. 

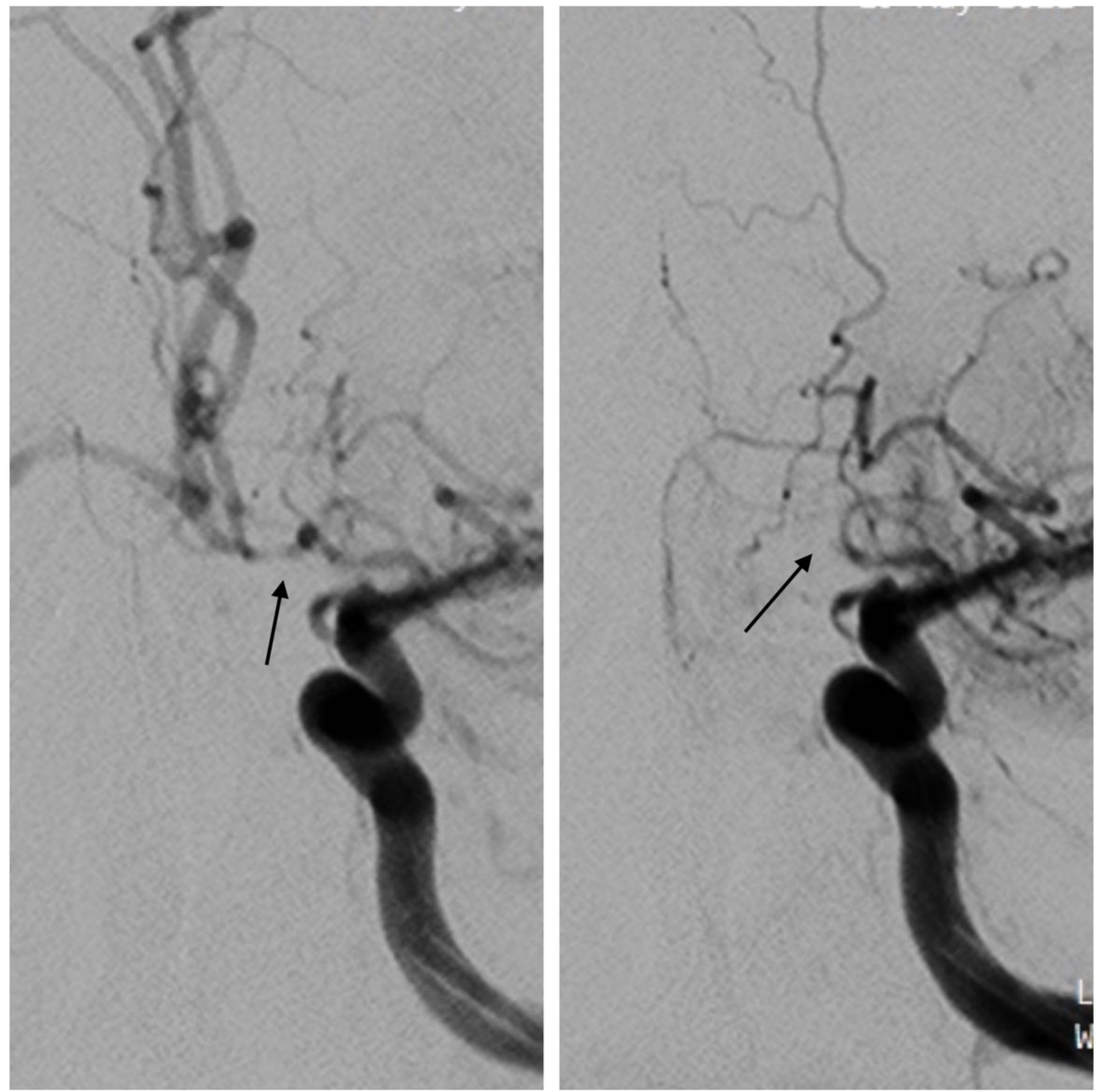

Figure 8

Post-procedure Digital Subtraction Angiography (DSA) of left internal carotid artery (ICA) showing absent flow in bilateral anterior cerebral artery (ACA) and right middle cerebral artery (MCA). 

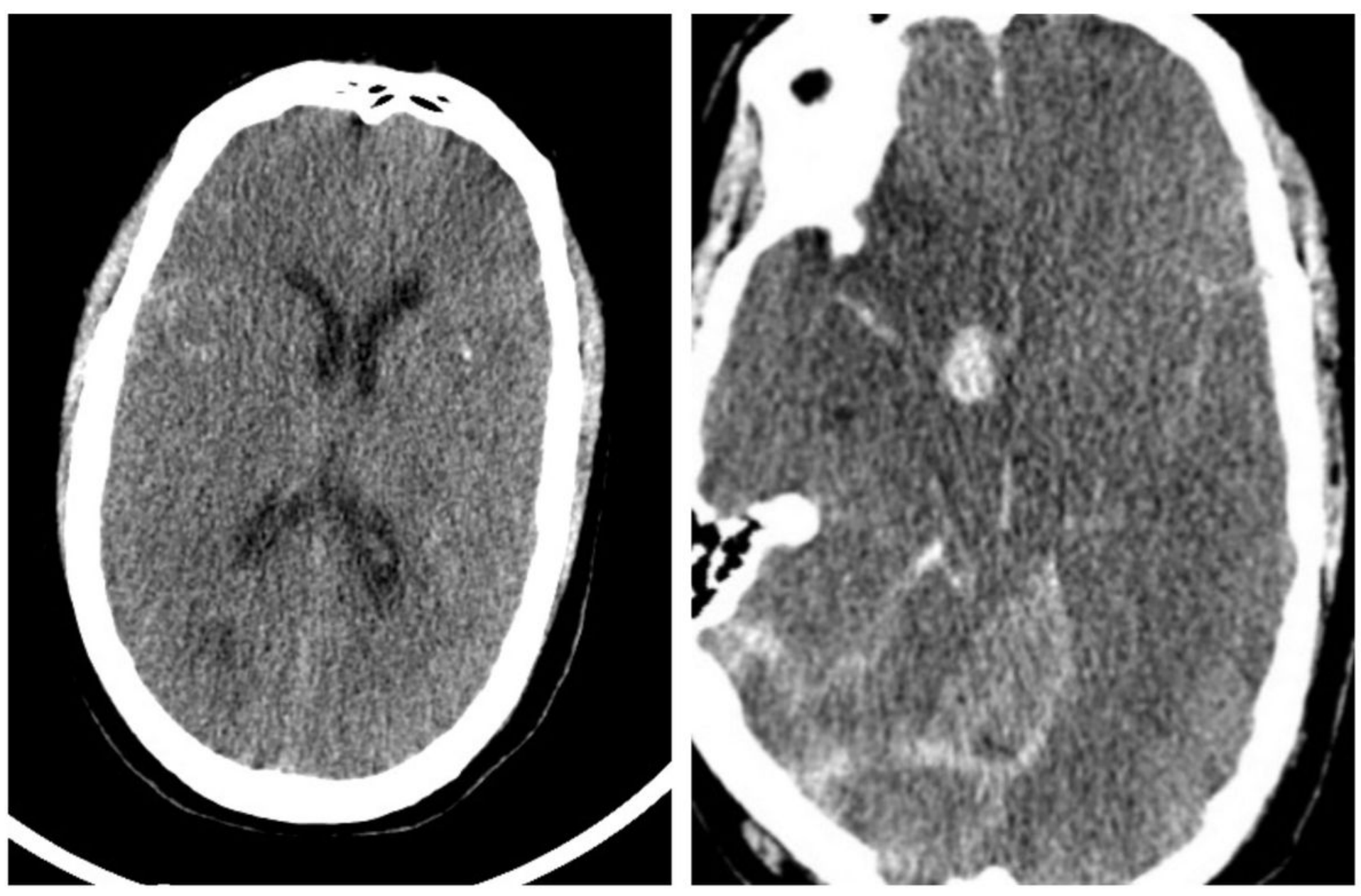

Figure 9

Post-procedure computer tomography head with 6 hours interval showing infarct in bilateral anterior cerebral artery (ACA) and right middle cerebral artery (MCA) territory followed by global infarct.

\section{Supplementary Files}

This is a list of supplementary files associated with this preprint. Click to download.

- CAREchecklistEnglish2013.docx 